\title{
Sexual strategies in the newts Triturus cristatus and Triturus marmoratus
}

\author{
Annie Zuiderwijk \\ Institute of Taxonomic Zoology, University of Amsterdam, P.O. Box 4766, 1009 AT Amsterdam, \\ The Netherlands
}

Keywords: Salamandridae, Triturus, courtship behaviour, sexual strategy, competition

\begin{abstract}
Courtship display characteristics are described and compared for the newts Triturus cristatus and $T$. marmoratus and patterns of male competitive behaviour are recognized. In interpreting the data, the operational sex ratio has to be taken into account, which was highly biased towards males in both species, more in $T$. marmoratus than in $T$. cristatus.

When sexual active, males of cristatus had more encounters than males of marmoratus, whereas the latter spent more time residing mating places. The male's display towards a female differed in time structure, variability and in behaviour characteristics. $T$. marmoratus display follows a fixed pattern; males succeeded better in restraining a female than males cristatus did. Courting males cristatus allowed other males to intrude. Malemale encounters were longer and playful in $T$. cristatus, more violent in $T$. marmoratus. Comparison with data from the literature indicates that courtship of $T$. marmoratus has more features in common with that of $T$. vittatus than it has with the courtship of $T$. cristatus.

It is suggested that in the course of evolution $T$. marmoratus adopted a strategy of Sexual Defense by means of territoriality and overt fighting, whereas $T$. cristatus in contrast adopted a strategy of Sexual Interference by female mimicry. Male display components that played a major role during the adaptation of competitive strategy are identified as the "whip" behaviour in $T$. marmoratus and the "rocking" behaviour in $T$. cristatus.
\end{abstract}

\section{Résumé}

Les caractéristiques de la parade nuptiale sont décrites et comparées pour les tritons Triturus cristatus et $T$. marmoratus, et sont reconnus les patrons du comportement compétitif des mâles. Dans l'interprétation des données il faut tenir compte de la sex-ratio des animaux sexuellement actifs: celle-ci penche nettement du côté des mâles pour les deux espèces (plus encore pour $T$. marmoratus que pour $T$. cristatus).

Lorsqu'ils sont sexuellement actifs, les mâles de cristatus ont plus de rencontres que ceux de marmoratus, mais ces derniers occupent plus de temps les endroits où se déroule l'accouplement. La parade du mâle pour une femelle se caractérise par sa structure temporelle, sa variabilité, ses particularités comportementales. La parade de $T$. marmoratus suit un patron fixe; les mâles de cette espèce enregistrent plus de succès dans la retention près d'eux d'une femelle, que ceux de cristatus. Les mâles de cristatus faisant la cour, permettent à d'autres mâles d'intervenir. Les rencontres mâle-mâle sont plus longues et plus ludiques chez $T$. cristatus, plus violentes chez $T$. marmoratus. La comparaison avec des données de la littérature indique que la parade nuptiale de $T$. marmoratus a plus de traits en commun avec celle de $T$. vittatus qu'avec celle de $T$. cristatus.

On suggère que, au cours de l'évolution, $T$. marmoratus a adopté une stratégie du type Sexual Defence par territorialité et combat actif, tandis que $T$. cristatus a adopté une stratégie du type Sexual Interference, en mimant le comportement de la femelle. On reconnaît comme composants de la parade nuptiale du mâle qui jouent un rôle majeur lors de l'adaptation de la stratégie compétitive, le comportement "coup de fouet" dans le cas de $T$. marmoratus, et le comportement "balancement" dans celui de $T$. cristatus.

\section{Introduction}

In studies on European newts of the genus Triturus, special attention has been paid to $T$. cristatus (superspecies) and $T$. marmoratus. These are distributed over most of Europe and have contiguous distribution areas, except for small zones of overlap (Thorn, 1968; Wallis \& Arntzen, 1989). In central France, $T$. cristatus and $T$. marmoratus when sharing breeding sites potentially hybridize producing 
unfit hybrids (White, 1946; Lantz \& Callan, 1954; Vallée, 1959; Zuiderwijk, in press). Studies have been done in the sympatric area (Schoorl \& Zuiderwijk, 1981) and in syntopic breeding sites (Zuiderwijk \& Bouton, 1987) on the effects of competition between these species and the efficacy of prezygotic reinforcing selection. The present paper contributes to this theme and is focussed on differences between $T$. cristatus and $T$. marmoratus in modes of courtship behaviour.

Following current theory, in Triturus sexual strategies appear to be determined by: (i) the dynamics of the breeding population, (ii) male-male competition for females, (iii) mate choice, and (iv) physiological constraints of reproductive performance (Verrell, 1989). As to the dynamics of a breeding population, a major factor is the sex ratio of adults, effectively the ratio of fertilizable females to sexually active males or the "operational sex ratio" (OSR) (Emlen \& Oring, 1977).

Competition exists among members of the more available sex for access to members of the limiting sex and increases with increasing skewness of the sexes (Verrell, 1989). For T. marmoratus as well as for $T$. cristatus inter-male competition for mating places and females has been described (Zuiderwijk \& Sparreboom, 1986). According to these authors territoriality is present in both species; however, the intensity and effectiveness of territoriality differ between the species. Territoriality and other types of competitive behaviour are likely to influence the sexual strategy adopted in a certain situation.

A study was carried out in a natural syntopic breeding site of $T$. cristatus and $T$. marmoratus. The following factors were quantified: (i) operational sex ratio, (ii) male sexual activity, (iii) malefemale and (iv) male-male interactions.

Besides intraspecific interactions, interspecific interactions were also observed, but these data have not been treated here, being the subject of a future paper.

\section{Material and methods}

\section{Study area}

Observations were made on natural syntopic breed- ing populations of $T$. cristatus and $T$. marmoratus in the department Mayenne, in France. The breeding pond is situated on a farmyard in between meadows and small patches of woodland. Pond size is approximately $8 \times 18 \mathrm{~m}$ (a more detailed description is given by Zuiderwijk \& Sparreboom, 1986).

A temporary bridge over the pond and a traject around it allowed for observations. Newt activities concentrated in open places, i.e. without vegetation on the pool bottom. Water depths ranged between 30 and $60 \mathrm{~cm}$ and transparence was enough to enable recognition of species and sex of the newts on the pool bottom. From the middle of April on, the water surface had to be cleaned every afternoon to permit observations during the subsequent evening. Part of the pond of approximately 45 square metres was used by the newts to aggregate for courtship. This part of the pond was dubbed "Arena". Males of $T$. cristatus and $T$. marmoratus aggregated in the Arena, starting at dusk, and occupying and defending a territory for some hours or a whole night.

Observations were made during two study periods from 5 to $31 \mathrm{March}$, and from 14 April to 14 May, 1986. The newts were observed by torch light with adjustable light intensity. The use of adjustable light proved essential for $T$. marmoratus, as this species is easily disturbed.

\section{Population characteristics}

Observations started at sunset when both species became sexually active. Males and females were considered sexually active when they were present on open spots in the Arena. The following parameters were recorded on audio-tape: species, sex, behavioural characteristics, locality, distance to nearest neighbour and its identity and sex. On average a full description of the newts and their activities in the Arena took about 60 minutes. In a typical night two descriptions were completed, with a one hour interval. The description of characteristics, their frequence and duration, and other variables were analyzed from the tapes.

The Operational Sex Ratio (OSR) was estab- 
lished daily for each species by counting of sexually active males and females. The average OSR was calculated from the summed data over the entire study period, for both species.

Overall sex ratios and population sizes were estimated in May, by means of capture-recapture methods. Eight males and seven females marmoratus from neighbouring ponds were introduced in the study pond during March.

\section{Male behavioural characteristics}

Three main categories of male behaviour were observed in the Arena:

Reside. Residing was scored when a male newt stayed motionless on the bottom, occupying a potential mating spot, with no other newts being present in a circle of $0.20 \mathrm{~m}$ radius.

Move. Moving around was scored when a male either swimming or walking over the bottom moved from one potential mating place to another.

Encounter. An encounter was scored each time when a male was in contact with a female or another male. Typically, an encounter would start with a male moving around approaching a residing male.

Male behavioural characteristics during an encounter were more fully described. In Triturus species a courtship goes through three distinct phases: orientation, display and spermatophore transfer. Displays. The display phase is the most species specific and the most time consuming part of a courtship. Displays were observed not only between male and female but also between males. A display phase could be short, especially in a second sperm transfer between the same partners. The shorter displays in this study are either part of interrupted male-female encounters, or of male-male encounters; the longer displays usually belonged to a courtship wherein sperm transfer happened. During displays the following male actions were observed (terminology used is after Halliday (1977, 1990; Sparreboom \& Arntzen, 1987; Green, 1989).

Cat-buckle ("Ready posture" in Green, 1989): The male's body is arched upward and kinked in the middle; the tail is slightly bent towards the partner. Cat-buckle is an attitude of exhibition.
Rocking ("Waggle" and "Fan" in Green, 1989): The male is standing on four legs and pushes with left and right foreleg alternately on the bottom, rocking his body from side to side, in phase with large amplitude tail waves in the direction of the partner.

Handstand: Standing on his forelegs, the male elevates hindlegs and hindbody to an almost vertical position; the tail is bent towards the partner in a wide angle.

Lean-in: The male elevates his hindbody and leans over sideways, covering the female's body.

Whip ("Lash" in Green, 1989): From the position of lean-in, the male delivers a powerful tail-lash, usually hitting the partner.

Shake-out (the movement was not described earlier; however, it is possibly synonymous with "Fadeout" in Green, 1989): The male undulates his tail in a series of beats that begins at the tail base and ends at the tail tip. The length of tail involved in each beat decreases in the series till the tail is still and stretched.

Sniff: Sniffing is scored when a male's snout touches another newt. Often the other one's snout or head, the flank or the cloaca region is touched. Push: Sniffing often precedes pushing. The observable difference is that the pushed newt actually gets replaced. Pushing occurs against the other one's head or flank, and can last several seconds.

Bite: A sudden movement by which a male newt snaps at another newt and keeps part of the other in its mouth, which often is a leg, or part of the tail, the flank, the crest or the head. Biting is easily to observe especially by the shocking reaction of the bitten animal. In the case of leg and tail biting, the bitten newt may hardly release.

Run after: Run after is scored when a newt is followed by another newt when trying to escape.

Male behavioural characteristics were quantified during the second study period when both species had established their maximum breeding populations. The $G$-test of independence was used to test significance of observed differences between the species in sex ratio and in numbers of male behavioural characteristics. The Student's $t$-Test for unpaired samples was used to test independence of time variables. 


\section{Results}

\section{Dynamics of the breeding populations}

The OSR of both species are shown in Table I, as percentages males and females. During the observation period the OSR did not change significantly in both species (Table I, b). Therefore, the OSR has been totalled over the entire observation period. OSR was 79 males to 21 females for $T$. cristatus and 89 males to 11 females for $T$. marmoratus, which is significantly different, except during 1-14 May (Table I, a). The proportion of sexually active females in $T$. cristatus appeared slightly higher in March, descending towards the end of the breeding period. The opposite tendency was registered for $T$. marmoratus, where the proportion of sexually active females ascended towards the end of the breeding period. These different tendencies most probably are the result of different migration behaviour: Most cristatus newts were present in the pond when breeding started, whereas most marmoratus newts entered the pond during the month of March, males preceding females, and the latter species had built up its breeding population only around the middle of April (cf. Bouton, 1986). Consequently, the difference in sex ratio between the two species was significant in March and April and not significant in May.

Population size estimates are shown in Table II. To allow for a comparison the frequencies of sexually active newts during May are listed in the same table.

The mean sexual activity of the cristatus male population was $42.2 \%$, which is more (not significantly) than the mean sexual activity of the marmoratus males, $35.6 \%$. Significantly lower were the proportions of active females: $9.6 \%$ cristatus females and $6.5 \%$ marmoratus females (Table II, a).

\section{Male behaviour}

1. Reside, move and encounter

Table III gives the scores of the three categories of male activity: reside, move, encounter. Encounters are further subdivided into male-male and malefemale encounters. The scores for reside, move and encounter can be interpreted as the amount of time that was spent to these categories of behaviour and therefore are expressed as percentages.

No temporal differences were observed in $T$. cristatus activities neither in $T$. marmoratus activities (Table III, b). Differences between species are apparent in the frequencies for reside and encounter. $T$. marmoratus males spent more time residing than $T$. cristatus males did, whereas the latter had more encounters. Both species spent a comparable amount of time in moving around.

The proportions male-female encounters were significantly higher in May than in April for both species (Table III, c); for $T$. marmoratus this is related to differences in OSR between April and May (see Table I). During the whole observation period the proportions male-female encounters in $T$. marmoratus were slightly, but not significantly, higher than in $T$. cristatus.

Table I. Operational Sex Ratio (OSR) for Triturus cristatus and T. marmoratus in the Arena in 1986. $N=$ summed frequencies of males and females.

\begin{tabular}{rlllll}
\hline & cristatus & & marmoratus & a) \\
& $N$ & OSR: male/female & $N$ & OSR: male/female & \\
\hline 05-31 March & 500 & $76 / 24$ & 160 & $91 / 9$ & $* * *$ \\
14-30 April & 624 & $81 / 19$ & 338 & $90 / 10$ & $* * *$ \\
01-14 May & 268 & $82 / 18$ & 150 & $86 / 14$ & N.S. \\
b) & & N.S. & & N.S. & $* *$ \\
total & 1392 & $79 / 21$ & 648 & $89 / 11$ & $* * *$ \\
\hline
\end{tabular}

$G$-test of independence, N.S. = not significant, ${ }^{* * *}=p<0.001$, a) one degree of freedom, b) two degrees of freedom. 
Table II. Population size estimate ( \pm standard deviation) for Triturus cristatus and $T$. marmoratus, and proportion of sexually active newts in the study pond in May, 1986.

\begin{tabular}{|c|c|c|c|c|c|c|}
\hline & $\begin{array}{l}\text { cristatus } \\
\text { males }\end{array}$ & females & a) & $\begin{array}{l}\text { marmoratus } \\
\text { males }\end{array}$ & females & a) \\
\hline Population size & $58( \pm 4)$ & $55( \pm 7)$ & N.S. & $43( \pm 7)$ & $38( \pm 13)$ & N.S. \\
\hline $\begin{array}{l}\text { Average number of } \\
\text { active newts }\end{array}$ & $24.5( \pm 5.2)$ & $5.3( \pm 2.3)$ & $* *$ & $15.3( \pm 3.3)$ & $2.5( \pm 1.7)$ & $*$ \\
\hline $\begin{array}{l}\text { Proportion sexually } \\
\text { active newts }(\%)\end{array}$ & $42.2 \%$ & $9.6 \%$ & & $35.6 \%$ & $6.5 \%$ & \\
\hline
\end{tabular}

$G$-test of independence, N.S. $=$ not significant, $*=p<0.05, * *=p<0.01$, a) one degree of freedom.

Table III. Scores of behavioural categories of active males of Triturus cristatus and T. marmoratus in the study pond, in April and May, 1986. In the right of the table encounters have been subdivided into male-male encounters $(m-m)$ and male-female encounters ( $m-f)$.

\begin{tabular}{|c|c|c|c|c|c|c|c|c|c|c|}
\hline & \multicolumn{2}{|c|}{ cristatus } & \multicolumn{2}{|c|}{ marmoratus } & \multirow[t]{2}{*}{ a) } & \multicolumn{2}{|c|}{ cristatus } & \multicolumn{2}{|c|}{ marmoratus } & \multirow[t]{2}{*}{ a) } \\
\hline & $N$ & $\%$ & $N$ & $\%$ & & $m-m$ & $m-f$ & $\mathrm{~m}-\mathrm{m}$ & $m-f$ & \\
\hline \multicolumn{11}{|l|}{ April: } \\
\hline Reside & 542 & $47 \%$ & 426 & $56 \%$ & $*$ & & & & & \\
\hline Move & 138 & $12 \%$ & 104 & $14 \%$ & N.S. & & & & & \\
\hline Encounter & 467 & $41 \%$ & 224 & $30 \%$ & $* *$ & $85 \%$ & $15 \%$ & $83 \%$ & $17 \%$ & N.S. \\
\hline \multicolumn{11}{|l|}{ May: } \\
\hline Reside & 218 & $41 \%$ & 160 & $50 \%$ & N.S. & & & & & \\
\hline Move & 74 & $14 \%$ & 48 & $15 \%$ & N.S. & & & & & \\
\hline Encounter & 239 & $45 \%$ & 115 & $35 \%$ & $* *$ & $78 \%$ & $22 \%$ & $74 \%$ & $26 \%$ & N.S. \\
\hline b) & N.S. & & N.S. & & & & & & & \\
\hline \multicolumn{11}{|l|}{ Total: } \\
\hline Reside & 760 & $45 \%$ & 586 & $55 \%$ & $* *$ & & & & & \\
\hline Move & 212 & $13 \%$ & 152 & $14 \%$ & N.S. & & & & & \\
\hline Encounter & 706 & $42 \%$ & 339 & $31 \%$ & $* *$ & $82 \%$ & $18 \%$ & $80 \%$ & $20 \%$ & N.S. \\
\hline
\end{tabular}

$G$-test of independence, N.S. $=$ not significant, $\left.{ }^{*}=p<0.05, * *=p<0.01, a\right)$ one degree of freedom, b) two degrees of freedom, c) one degree of freedom.

\section{Display towards females}

An encounter among a male and a female newt generally started with a short phase of orientation, followed by a more prolonged phase of display. Males of $T$. cristatus and $T$. marmoratus began their display phase after assuming an attitude of exhibition towards the partner (cat-buckle). The display phase appeared to have repeated series of male movements; one series is called a bout in this study (cf. Green, 1989). In Table IV, duration and number of bouts per display are shown for both species; only prolonged displays have been considered. Entire displays of $T$. marmoratus were shorter (not significantly), as were the single bouts (significantly), and this species had significant more bouts per display (Table IV, a). Bouts in $T$. cristatus were highly variable in duration.

The form of a single bout of a male cristatus was quite different from that of one in $T$. marmoratus. A display bout of a male $T$. cristatus included a lean-in, followed by several rocking beats (Fig. 1) or rarely by a whip. When a whip followed a leanin, the bout was very short; when rocking behaviour followed on lean-in, the bout could be long, dependent on the number of successive rocking beats. A minimum of three and a maximum of 38 rocking beats were scored per bout, one beat lasting 1.8 seconds on average. A display bout of a male $T$. marmoratus consisted of subsequently handstand, lean-in (Fig. 2), whip, and then return- 
Table IV. Time structure in prolonged male-female displays of Triturus cristatus and T. marmoratus.

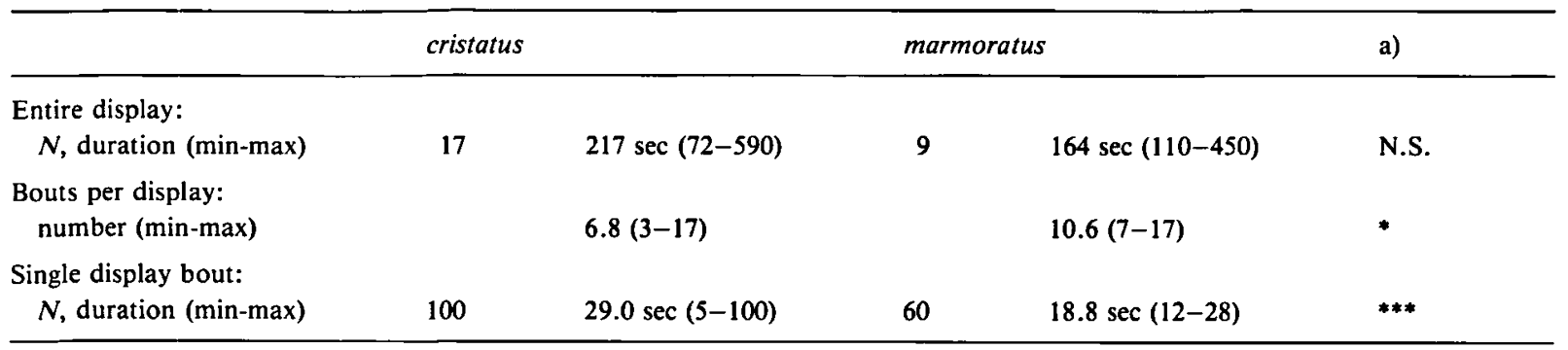

Student's $t$-test, a) level of significance of independence, N.S. $=$ not significant, ${ }^{*}=p<0.05,{ }^{* * *}=p<0.001$.

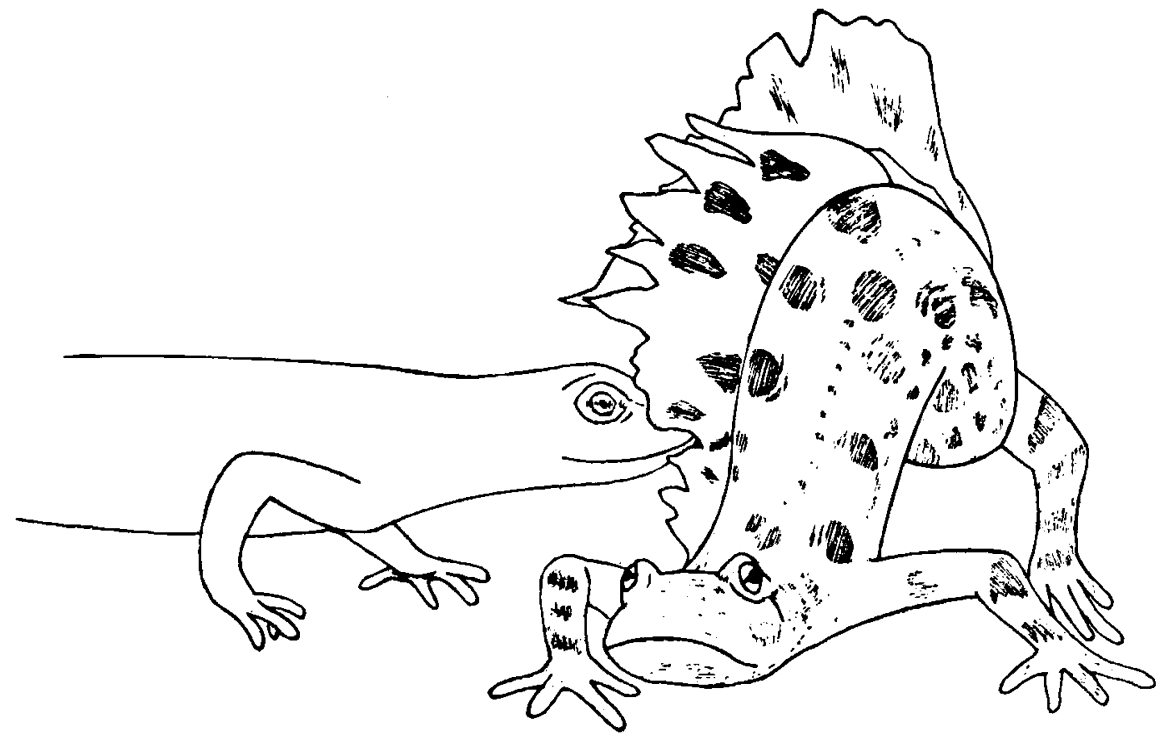

Fig. 1. A single male behaviour in Triturus cristatus, "rocking" in front of a female.

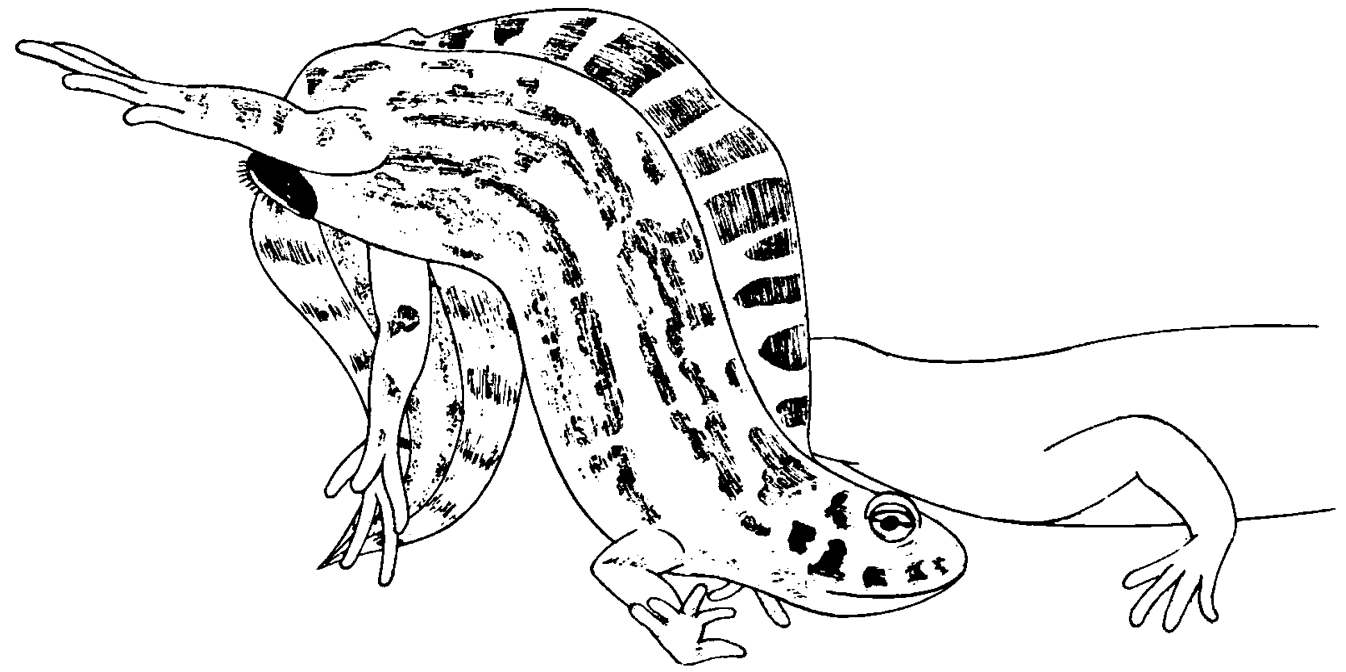

Fig. 2. A single male behaviour in Triturus marmoratus, lean-in. 
ing to the starting posture while shaking-out the tail. A marmoratus display had a more fixed pattern than a cristatus display, by the unvariable sequence of behaviour characteristics in its bouts. Coming to handstand and lean-in took half of the time of a bout; giving the whip, returning to the starting position and shake-out the tail took the other half of time.

The whip appeared to be a most powerful tail action, by which the male regularly hitted the female's body and often shifted her (or himself) some inches away. Such a whip was the high point of each bout of a $T$. marmoratus display and was shown in each bout, every $18.5 \mathrm{sec}$ on average. Rocking, being a marked rhythmic movement of the body with tailwaves in the same rhythm, made up $80 \%$ of the time of a cristatus display. It rendered cristatus display seem quiet, compared to marmoratus display. Males of cristatus did deliver whips, but only incidentally, and usually at the end of the whole display phase. A whole cristatus display included 1.4 whips on average; a marmoratus display 10.4 whips. Shake-out, a tail movement regular seen at the end of each marmoratus bout, might be the same as "Fade-out", a movement Green (1989) observed during displays of $T$. cristatus. However, shake-out, as described in Material and methods, has not been observed in $T$. cristatus during the present study.

It can be concluded that displays of $T$. cristatus and $T$. marmoratus are very different, in the first place because the species show different behaviours. Furthermore $T$. marmoratus displays are shorter but much more powerful and they cause more physical contact.

\section{Display towards males}

An encounter between males took place any time a male approached another male within a critical distance. Both males then take up an attitude of exhibition, like in a male-female encounter, after which a display develops with the characteristics of a male-female display.

The course of a male-male display appeared to be less predictable than a male-female display, although descriptions can be given of the more commonly seen courses.
Two cristatus males will make a cat-buckle, then lean-in and start rocking or, more frequently, just one male rocks whereas the other sniffs at the rocking male in the flank region. Sniffing can pass into pushing, after which one male disappears. When a male sniffs the cloaca region of another male, the other may suddenly turn and swim away. Two displaying males often attracked a third male. Interactions among two or three males cristatus were the more commonly seen encounters (Fig. 3).

Two marmoratus males will show an attitude of exhibition while they may sniff each other's head. Most commonly both males lean-in and one male delivers a whip after which the other disappears. The disappearing male may be followed ("run after") and sometimes bitten by the opponent (Fig. 4).

Table V shows the behavioural characteristics of 20 displays among cristatus males and 20 displays among marmoratus males. Clearly, the main components of male-female displays are also commonly seen in male-male displays: rocking being present only in cristatus; handstand, lean-in, whip, and shake-out in marmoratus. Sniff, push, bite, and run after are newly mentioned characteristics, that were not observed when males displayed towards females. Sniff and push were especially present in

Table $\boldsymbol{V}$. Scores of behavioural characteristics in male-male displays of Triturus cristatus and $T$. marmoratus. Scores out of 20 displays of each species have been summed; the min-max values, between parentheses, concern single displays.

\begin{tabular}{lccl}
\hline & cristatus & marmoratus & a) \\
\hline Cat-buckle & $33(0-2)$ & $17(0-2)$ & N.S. \\
Handstand & $4(0-1)$ & $19(0-2)$ & $* * *$ \\
Lean-in & $18(0-3)$ & $28(1-2)$ & $*$ \\
Whip & $3(0-1)$ & $19(0-3)$ & $* * *$ \\
Rocking & $76(0-17)$ & 0 & $* * *$ \\
Shake-out & 0 & $13(0-2)$ & $* * *$ \\
Sniff & $40(0-5)$ & $17(0-3)$ & N.S. \\
Push & $8(0-3)$ & $4(0-2)$ & N.S. \\
Bite & $1(0-1)$ & $7(0-3)$ & $*$ \\
Run after & $2(0-1)$ & $5(0-1)$ & N.S. \\
Duration (min-max) & $34 \sec (7-110)$ & 14 sec (3-30) & $* * b)$ \\
\hline
\end{tabular}

$G$-test of independence, N.S. = not significant, ${ }^{*}=p<0.05$, ${ }^{* * *}=p<0.001$, a) one degree of freedom, b) Student's $t$-test, level of significance of independence, ${ }^{* *}=p<0.01$. 


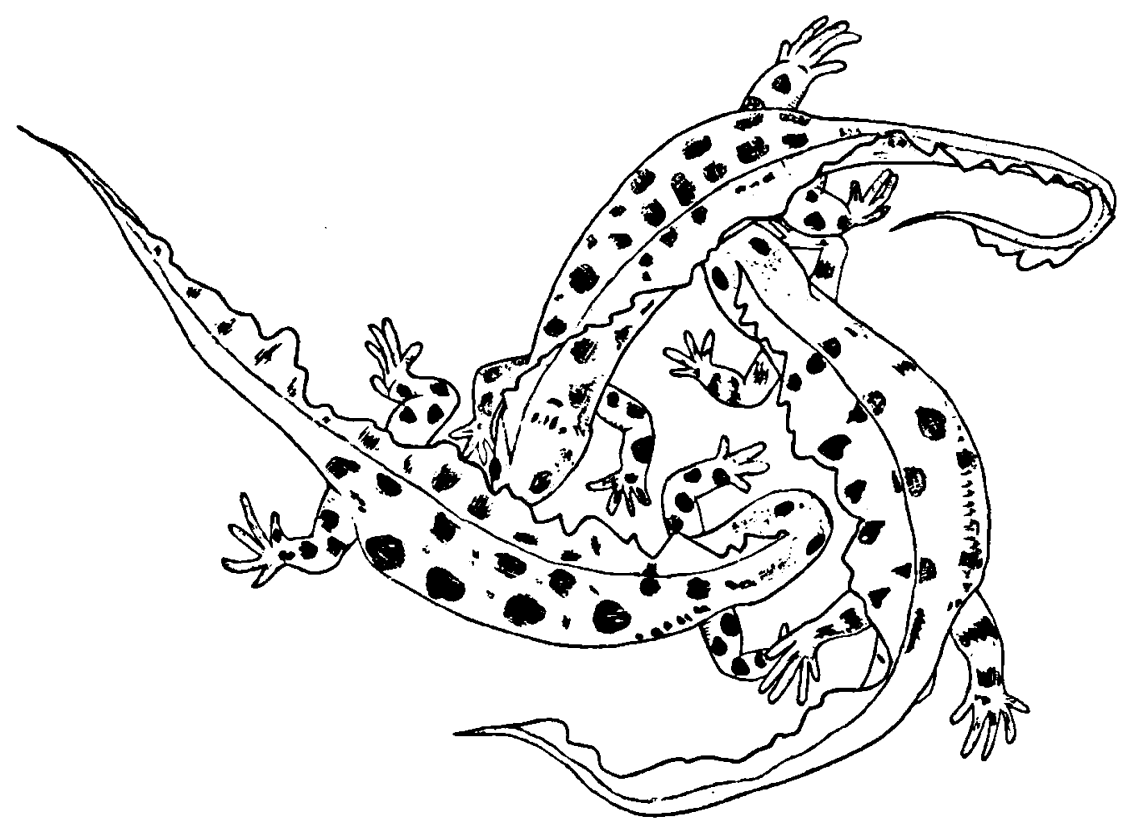

Fig. 3. Multiple male behaviour in Triturus cristatus, three males displaying.

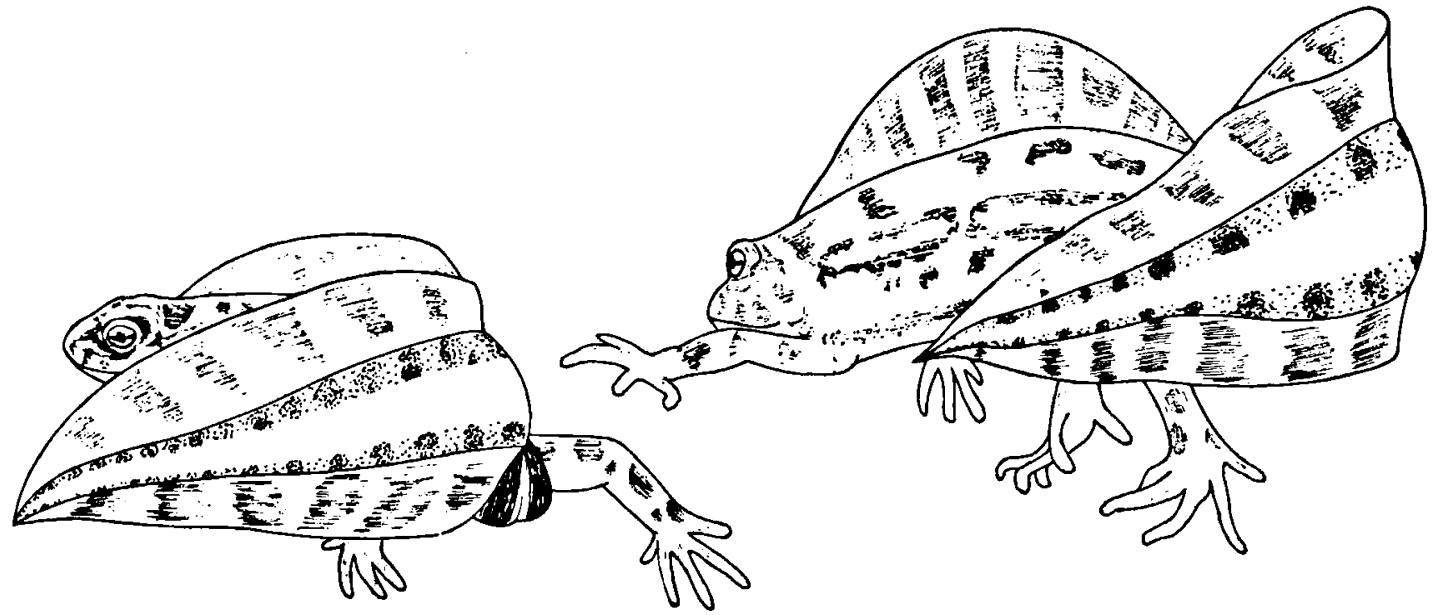

Fig. 4. Two males of Triturus marmoratus displaying. One of them just finished a "whip" whereafter the other one turns off.

cristatus (not significantly) and bite (significantly) and run after in marmoratus.

Concerning male-male display, the main difference between the species lies in the more violent (whip) and aggressive (bite, run after) behaviour of marmoratus males relative to cristatus males. Whip and bite used to end a male-male display (Fig. 4), which may explain the significant shorter duration of $T$. marmoratus male-male displays. The longer displays in $T$. cristatus seemed to have an element of play, especially because of the circumstance that displaying males attracted other males (Fig. 3).

\section{Matings}

During the entire period of observation 17 long displays between male and female $T$. cristatus were ob- 
served. Seven of them were brought to a premature end by the female's disappearing. Only three displays were followed by a successful sperm transfer between the partners that had started the display. One of these three couples had a second successful sperm transfer. Three displays were stopped by interrupting males, chasing the female away. In four others, an interrupting male stole the female of a courting male; in one of these, the intruding male took over the display; in the other three cases the female was stolen at the start of the sperm transfer phase. Active female mimicry of the interrupting male was observed twice (Fig. 5), the male nudging at the cloaca region of the original courting male when this had started to creep for sperm deposition. In three of the four cases the interrupter succeeded in inseminating the stolen female. This phenomenon is called Sexual Interference and hitherto only described for T. vulgaris (cf. Verrell, 1984).

Nine prolonged male-female displays of $T$. marmoratus were observed. Six of the nine displays were successfully finished by the male that had initiated the courtship. Three of those matings were followed by another sperm transfer between the same partners. Three displays were stopped by interrupting males. One of these interruptions caused a violent fight: With the female gone, the courting male (A) continued whipping in the absence of a mate. It was then sniffed at its tail tip by the interrupting male (B). Male A suddenly turned around; both males now taking handstand position, proceeding to lean-in, and whip, whereafter male $A$ pushed the head of male B, bit the head two times and the left frontleg. Male B escaped, followed by male $\mathrm{A}$.

Matings did not occur frequently enough to enable statistical testing of the observed differences. However, in conclusion can be said that courtship in $T$. cristatus and $T$. marmoratus in the studied pond differs in the following aspects:

1. Successful Sexual Interference occurs frequently in $T$. cristatus and is rare or absent in $T$. marmoratus.

2. Interrupting $T$. cristatus males may be successful in stealing the female. This was not observed for $T$. marmoratus.

3. Unlike $T$. marmoratus, successful sperm transfer among the partners that initiated courtship is rare in $T$. cristatus.

4. Successful sperm transfers are more frequent in $T$. marmoratus than in $T$. cristatus.

\section{Discussion}

The following discussion is based on observations of newts from a single mixed breeding place during a single mating season. It is not known to what extent these observations are typical of the species studied. Especially the high population densities in the pond may have been of influence. On the other hand these high densities may have accentuated the general differences between the two species. To solve this problem, more research should be done in natural populations of $T$. cristatus and $T$. marmoratus in both allotopic and syntopic populations.

\section{Dynamics of the breeding populations}

Studies on male courtship strategies in the setting of natural populations indicate the overall importance of the concept of OSR, the ratio of fertilizable females to sexually active males. OSR influences the intensity of inter-male competition and courtship frequency. The OSR is determined by several factors: duration of the breeding period, adult sex ratios, male and female mating capacity, and population density (Emlen \& Oring, 1977; Verrell, 1989).

In the present study the OSR of $T$. cristatus and $T$. marmoratus was directly measured and the influences of the supposed determinants were also observed:

1. A prolonged breeding period should effect the asynchronous sexual activity towards an excess of males, because single females are receptive only for a short time, whereas males remain in breeding condition throughout the season. In both species the breeding period was fairly long indeed, lasting more than two months, and lasting longer in $T$. cristatus than in $T$. marmoratus. When the observations started at the 6 th of March, most $T$. crista- 


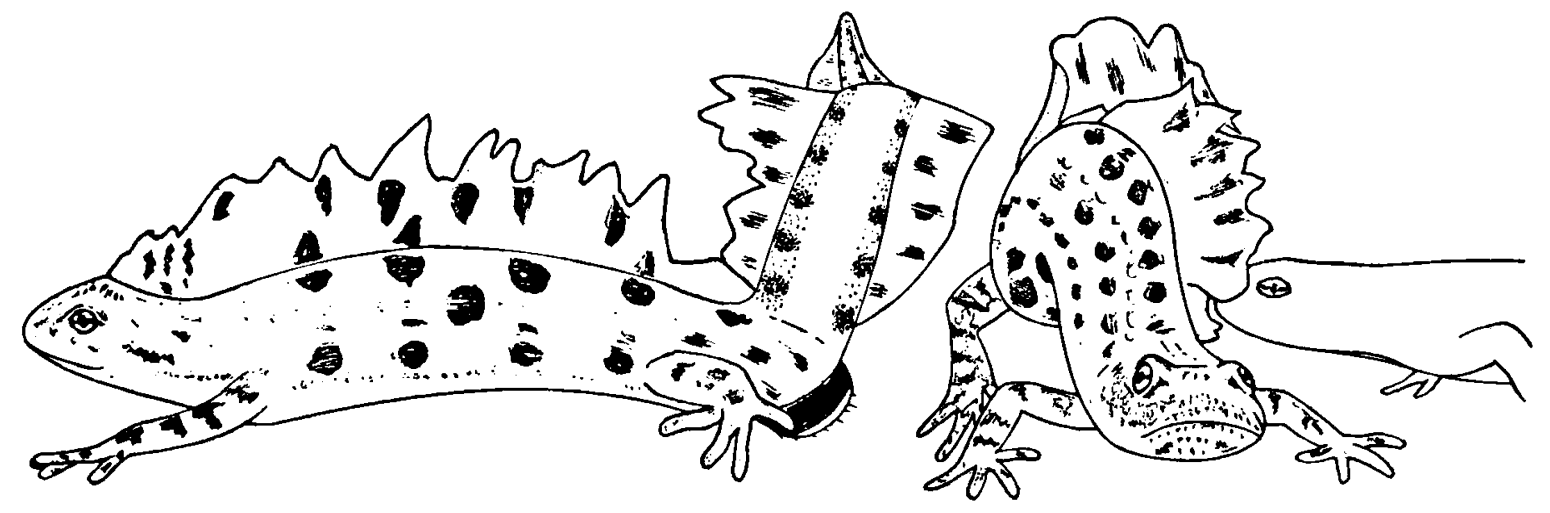

Fig. 5. Male-female behaviour, sexual interference by female mimicry in Triturus cristatus. The interrupting male blocks the female in following the originally courting male.

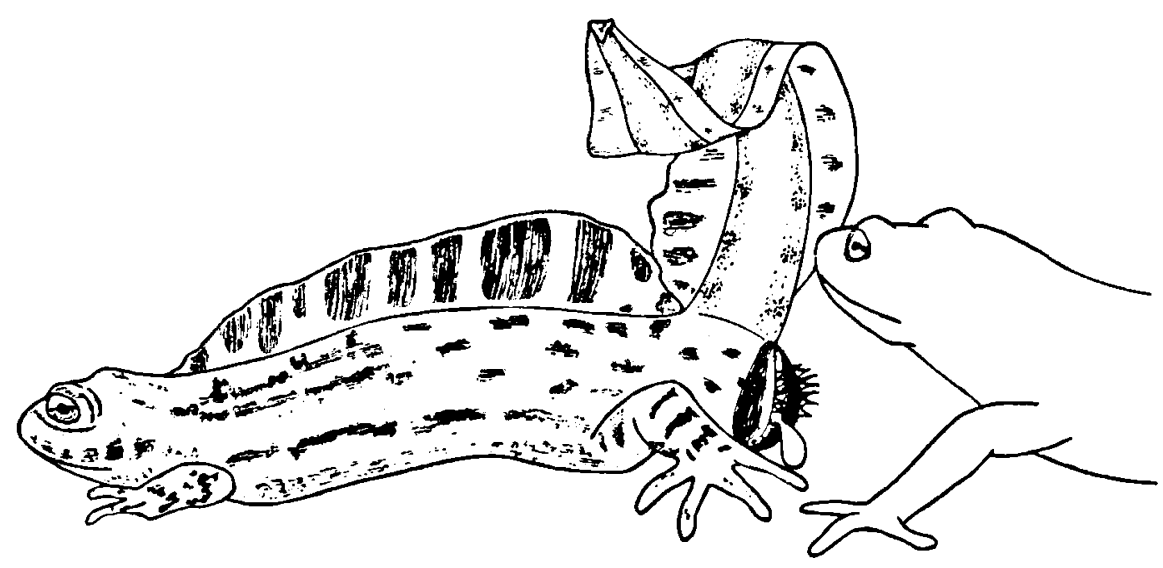

Fig. 6. Male-female behaviour, sperm deposition of a male Triturus marmoratus who is followed by the female.

tus newts were present in the breeding site, and most $T$. marmoratus newts arrived during that month. Both species' breeding activities continued till mid May.

2. The overall adult sex ratios appeared close to fifty-fifty at the end of the breeding period (Table II), but were quite different for $T$. marmoratus at the beginning. Most marbled newts migrated towards the pond during the month of March, males preceding females (Bouton, 1986), which caused an excess of males in the beginning of the season. Consequently, OSR in T. marmoratus was strongly skewed towards males in March, with an average of one female to ten males during that period.

3. The influence of male and female mating capacity. The proportions of sexually active newts, males and females, could only be given for the month of May, when the population sizes had been estimated. The percentages in Table II demonstrate the asynchronous sexual activity in males and females. Active males outnumbered responsive females about four times in $T$. cristatus and about five times in $T$. marmoratus. On average, $42.2 \%$ of the $T$. cristatus males were ready to mate (the maximum score was $72 \%$ ) and $9.6 \%$ of the females (maximum $20 \%$ ), which made them sexually more active than $T$. marmoratus males and females with respectively $35.6 \%$ (maximum 56\%) and $6.5 \%$ (maximum $13 \%$ ). $T$. marmoratus females had the lowest mating capacity.

Apparently due to the above mentioned influences, and especially by the asynchronous sexual activity in males and females, the OSR measured 
was biased towards males in both species during the whole period, and more in $T$. marmoratus than in $T$. cristatus, especially during March.

As a result of the OSR values, according to Emlen \& Oring (1977), a high degree of inter-male competition for access to fertilizable females could be expected and, because the OSR was more skewed in $T$. marmoratus than in $T$. cristatus, more competition might occur between $T$. marmoratus males than between $T$. cristatus males.

\section{Competition}

Verrell (1989) classified four different types of competitive behaviour patterns to occur between males in the Salamandridae, three of which were known in Triturus, viz: terrioriality, observed in $T$. cristatus, T. marmoratus and T. vittatus (Zuiderwijk \& Sparreboom, 1986; Raxworthy, 1989); sexual interference, observed in $T$. vulgaris (Verrell, 1984); overt fighting, observed in $T$. vittatus (Raxworthy, 1989). All three strategies could be recognized in the breeding pond as will be discussed below.

Territoriality. In an earlier paper (Zuiderwijk \& Sparreboom, 1986) it has been described how males of $T$. cristatus and $T$. marmoratus space out in the Arena and occupy small locations, potential mating places, which they defend against other males. The behaviour was interpreted as being territorial, in accordance with the definition of Brown \& Orians (1970) that territoriality is the defense of a specific location against conspecific individuals. Defense of the mating place by males of $T$. marmoratus was very common and appeared to be a well-developed, successful strategy in keeping off rivals. Lean-in and whip, the main components of the species display repertoire, were the tools by which a residing male successfully and rapidly chased away intruding males. A T. marmoratus male display never lasted long (Table V). Not only mating sites were defended by $T$. marmoratus males, but also females. The defense of a receptive female by a courting male was more aggressive than the defense of a location. The actions push, bite, and run after were seldomly seen when the male defended a mating place and were more often seen when defending a receptive female.

Territorial behaviour in $T$. cristatus was less effective. Males spaced out like $T$. marmoratus males and occupied a mating place. When another male approached, the resider displayed to him: lean-in and rocking. However, $T$. cristatus' rocking was less effective than T. marmoratus' whips. Intruding males reacted by sniffing the cat-buckled flank of the residing male, instead of disappearing. Consequently a male display in $T$. cristatus lasted longer than in $T$. marmoratus, and rocking, sniffing and pushing were the main components (Table V). Whips were delivered rarely and biting has been recorded only once. An inter-male display ended when one male broke away; this could either be the intruder or the residing male. Green (1989) who paid attention to inter-male behaviour when studying courtship of $T$. cristatus in aquariums, could not agree with the conclusion of territoriality for this species, since aggressive behaviour components were not recorded in his experiments. More investigations on this subject should be done in the species' natural surroundings, since observations on natural populations reveal unexpected behavioural components. As stated before: the way $T$. marmoratus defended its place and its partner is unambiguous, simply by its unvariable effectiveness.

Overt fighting. Biting was a component of malemale behaviour in $T$. marmoratus, as described before, and was seen only once in $T$. cristatus. Pushing, on the other hand, was often seen among males of $T$. cristatus. The aggressive character of pushing in $T$. cristatus is questionable, however (see later).

Sexual interference by female mimicry. Sexual interference appeared the rule rather than the exception in courtships of both species, although less so in $T$. marmoratus than in $T$. cristatus. Certainly the high population densities were of influence (Verrell, 1989). Most frequently courtship was brought to a premature end by interruption of other males causing the female to swim away. Sexual interference by female mimicry was observed in $T$. cristatus, but not in T. marmoratus. The classic example 
of female mimicry in the genus Triturus, as described for the first time by Verrell (1984) for $T$. vulgaris (in which an interrupting male nudges the cloaca region of the courting male, stimulating the last to fullfill the spermatophore deposition, while preventing the female to follow the originally courting male), has been observed five times in a $T$. cristatus display. In three of these cases the interrupter inseminated the stolen female. The other two cases were seen in male-male displays, when one of the displaying males turned around after some time, the tail folded upwards, upon which the other male nudged the cloaca region of the creeping male. Female mimicry in the absence of a female means that the mimicking male does not win a female but his result is the departure of a competitor and winning a location. Female mimicry among males in the absence of females has not been reported before, as far as I know. On the basis of the observations mentioned above it is worth while to analyse more closely the components of $T$. cristatus malemale behaviour.

When two or three males were displaying, most commonly one of the males was rocking while the other(s) sniffed or nudged the rocking male on the head, in the flank or in the cloaca region. These movements are not part of the regular display repertoire of courting males, but are normally shown by courted females who are sexually receptive and stimulate the courting male to continue. Consequently, we should consider males that nudge or sniff a courting other male as female mimicking. If this is true, female mimicry apparently is well developed in $T$. cristatus and was very often demonstrated in the population studied; and obviously, male $T$. cristatus has adopted both typical male courtship behaviour and female behavioural components. The movements he utilizes during an encounter apparently depend on whether the partner he encounters is already displaying himself or not.

According to this view we can expect the male $T$. cristatus to display as follows: When a sexually active male meets a female or another male, he will display its lean-in and rocking bouts. When a male approaches an already displaying male, whether the latter is displaying to a female or a male, the approaching male will show the female components of nudging the head and the flank of the courting male. This interpretation of the observations seems to be correct (Table V). The benefit in the first case is, that the intruder gains a "ready-to-mate-female", without paying the costs of an energy consuming display; in the second case that the intruder wins the location.

Following this theory, sexual interference by female mimicry is the strategy by which $T$. cristatus males compete for matings and for mating sites. The fact that males are strongly attracted to rocking males suggests this strategy to be successful for individual males.

I conclude that $T$. marmoratus and $T$. cristatus adopted different competitive male strategies in their courtship behaviour. In $T$. marmoratus Sexual Defense by means of territoriality and overt fighting is predominant while in $T$. cristatus Sexual Interference by female mimicry is apparent. The differing strategies may have had different impact on mating success: $T$. marmoratus males restrained females better than $T$. cristatus males did. Displays in T. marmoratus showed higher rate of successful sperm transfer and accordingly, a higher mating success. The mating success of $T$. cristatus is lower but may have been affected by its high density. Giacoma \& Crusco (1987) found this effect in a population of $T$. italicus, where a high rate of sexual interference was accompanied by a low rate of spermatophore transfer.

\section{Evolution of behavioural characteristics}

Triturus cristatus, $T$. marmoratus and $T$. vittatus share a number of courtship features. They have a stable lek-system, defend display sites and share some typical postures as cat-buckle, handstand and lean-in (Zuiderwijk \& Sparreboom, 1986; Sparreboom \& Arntzen, 1987; Raxworthy, 1989). T. vittatus and $T$. marmoratus have features that are not shared with $T$. cristatus. They show a male competitive strategy of sexual defense by means of territoriality and overt fighting, especially $T$. vittatus. Moreover, they share the whip as the major component in their display. In the light of recent phylogenetic studies, that strongly argue in favour of a 
monophyletic origin of $T$. cristatus (superspecies) and T. marmoratus (cf. Bucci-Innocenti et al., 1983; Rafinski \& Arntzen, 1987; Arntzen \& Sparreboom, 1987, 1989; Giacoma \& Balletto, 1989), it is surprising that $T$. marmoratus shares more courtship features with $T$. vittatus than with $T$. cristatus. Considering the high potential of adaptation of behaviour characters, the use of courtship characters to reconstruct phylogeny can be questioned (Halliday, 1990; Green, 1989).

The current opinion on the nature of sexual strategies is that sexual interference is a very old feature as it occurs in several families of Salamandridae and that sexual defense is an adoption to prevent sexual interference (Verrell, 1989; Giacoma \& Balletto, 1989; Halliday, 1990). Following this hypothesis and assuming that $T$. cristatus (superspecies ) and $T$. marmoratus form a monophyletic group, then the sexual defense strategies in $T$. marmoratus and $T$. vittatus would present an example of convergent evolution. It could be conceived that the parent species of these newts possessed both strategies, probably in a less elaborated state. Possibly the ancestor of $T$. marmoratus and the ancestor of $T$. vittatus underwent comparable selection pressure for adopting sexual defense as main strategy, together with the selection of the whip as major component of courtship. These parallel selections may have been influenced by female choice. The ancestral $T$. cristatus, on the other hand, possibly adopted sexual interference as the most successful competing strategy, in combination with the development of rocking. In this case the selection was most probably not influenced by female choice.

Species in which males successfully defend their partner, like $T$. vittatus and $T$. marmoratus, are sensitive to selection through female choice: Higher crest, larger body size and production of pheromones are suggested to have selective value (Malacarne \& Cortassa, 1983; Hedlund, 1990). The selective value of these characters has only been studied in T. cristatus. Hedlund (1990) found positive correlations between mating success and crest height of males in $T$. cristatus; Malacarne \& Cortassa (1983) found mating success correlated with pheromone production in $T$. carnifex. These studies did not demonstrate, however, that the relationship is due to female choice (Green, 1989). The present study indicates that in $T$. cristatus female choice is not effective. If stolen matings in T. cristatus are as common in general as in the studied population, a demonstrable selective effect of female choice seems unlikely.

A specific characteristic in $T$. cristatus populations is the high proportion of young (and small) animals, juveniles and subadults, living together with the adults in the breeding pond, a situation which does neither occur in $T$. marmoratus, nor in $T$. vittatus, where juveniles and young adults stay on land. The question arises here, whether this ecological feature coevolved or was a distinctive factor of influence.

\section{Acknowledgements}

I am grateful to Peter Mudde and Mr. J. Martin who made the drawings and to Wim Bergmans for his encouraging help and corrections of the English. Thanks are also due to Pim Arntzen and Rose Blommers-Schlösser for suggestions and comments on an earlier version of the manuscript and to Willem Langeveld and Florence Pieters for reading it.

\section{References}

Arntzen, J.W. \& M. Sparreboom, 1987. The use of biochemical and behavioural data for the phylogeny of the Old World newts, genus Triturus. Proc. Fourth Ord. Gen. Meet. Societas Europaea Herpetologica, Nijmegen 1987: 25-28.

Arntzen, J.W. \& M. Sparreboom, 1989. A phylogeny of the Old World newts, genus Triturus: biochemical and behavioural data. J. Zool., Lond., 219: 645-664.

Bouton, N., 1986. Données sur la migration de Triturus cristatus et $\mathrm{T}$. marmoratus (Urodela, Salamandridae) dans le département de la Mayenne (France). Bull. Soc. herp. Fr., 40: 43-51.

Brown, J.L. \& G.H. Orians, 1970. Spacing patterns in mobile animals. Ann. Rev. Ecol. Syst., 1: 239-262.

Bucci-Innocenti, S., M. Ragghianti \& G. Mancino, 1983. Investigations of karyology and hybrids in Triturus boscai and $\mathrm{T}$. vittatus, with a reinterpretation of the species group Triturus (Caudata: Salamandridae). Copeia, 1983: 662-672.

Emlen, S.T. \& L.W. Oring, 1977. Ecology, sexual selection and the evolution of mating systems. Science, 197: 215-223.

Giacoma, C. \& E. Balletto, 1989. Phylogeny of the salamandrid genus Triturus. Boll. Zool., 55: 337-358.

Giacoma, C. \& N. Crusco, 1987. Courtship and male interference in the Italian newt: a field study. Monit. zool. Ital., (n.S.) 21: 190-191. 
Green, A.J., 1989. The sexual behaviour of the great crested newt, Triturus cristatus (Amphibia: Salamandridae). Ethology, 83: 129-153.

Halliday, T.R., 1977. The courtship of European newts. An evolutionary perspective. In: D.H. Taylor \& S.I. Guttman, eds., Reproductive biology of amphibians: 185-232 (Plenum Press, New York).

Halliday, T.R., 1990. The evolution of courtship behavior in newts and salamanders. Adv. Study Behav., 19: 137-169.

Hedlund, L., 1990. Factors affecting differential mating success in male crested newts, Triturus cristatus. J. Zool., Lond., 220: 33-40.

Lantz, L.A. \& H.G. Callan, 1954. Phenotypes and spermatogenesis of interspecific hybrids between Triturus cristatus and T. marmoratus. J. Genet., 52: 165-185.

Malacarne, G. \& R. Cortassa, 1983. Sexual selection in the crested newt. Anim. Behav., 31: 1256-1257.

Rafinski, J. \& J.W. Arntzen, 1987. Biochemical systematics of the Old World newts, genus Triturus: Allozyme data. Herpetologica, 43: 446-457.

Raxworthy, C.J., 1989. Courtship, fighting and sexual dimorphism of the Banded Newt, Triturus vittatus ophryticus. Ethology, 81: 148-170.

Schoorl, J. \& A. Zuiderwijk, 1981. Ecological isolation in Triturus cristatus and Triturus marmoratus (Amphibia: Salamandridae). Amphibia-Reptilia, 1: 235-252.

Sparreboom, M. \& J.W. Arntzen, 1987. A survey of behaviour in the Old World newts (genus Triturus). Proc. Fourth Ord. Gen. Meet. Societas Europaea Herpetologica, Nijmegen 1987: 369-372.
Vallée, L., 1959. Recherches sur Triturus blasii de l'Isle, hybride naturel de Triturus cristatus Laur. $\times$ Triturus marmoratus Latr. Mém. Soc. zool. Fr., 31: 1-95.

Verrell, P.A., 1984. Sexual interference and sexual defense in the smooth newt, Triturus vulgaris (Amphibia, Urodela, Salamandridae). Z. Tierpsych., 66: 242-254.

Verrell, P.A., 1989. The sexual strategies of natural populations of newts and salamanders. Herpetologica, 45(3): 265-282.

Wallis, G.P. \& J.W. Arntzen, 1989. Mitochondrial DNA variation in the crested newt superspecies: limited cytoplasmic gene flow among species. Evolution, 43: 88-104.

White, M.J.D., 1946. The spermatogenesis of hybrids between Triturus cristatus and T. marmoratus (Urodela). J. exp. Zool., 102: 179-207.

Zuiderwijk, A., in press. Hybride Triturus cristatus et Triturus marmoratus. In: J. Castanet \& R. Guyétant eds., Atlas de répartition des Amphibiens et Reptiles de France. Société Herpétologique de France, Paris.

Zuiderwijk, A. \& N. Bouton, 1987. On competition in the genus Triturus (Caudata, Salamandridae). Proc. Fourth Ord. Gen. Meet. Societas Europaea Herpetologica, Nijmegen 1987: 453-458.

Zuiderwijk, A. \& M. Sparreboom, 1986. Territorial behaviour in Crested Newt Triturus cristatus and Marbled Newt T. marmoratus (Amphibia, Urodela). Bijdr. Dierk., 56(2): 205-213.

Received: 29 November 1989

Revised: 22 January 1990 